\title{
Using RSS 2.00 as a Model for u-Learning to Develop e-Training in Saudi Arabia
}

\author{
Mohammad A. Amasha and Salem Alkhalaf
}

\begin{abstract}
The main intent of the current research is to design a training program based on integration between RSS 2.0 as a model of ubiquitous learning (u-learning) and social media networks, namely the online social networking service Facebook as a model of social communication. The research tests also the effectiveness of the proposed program. The researchers made use of Facebook as an element within the system of social communication networks. The developmental method-used in instructional technology research-was employed to develop the training program. Moreover, the researchers used the experimental method while administering the program and assessing its effectiveness via a sample derived from general-education teachers from Qassim Educational District, K.S.A. The sample was purposely selected. It amounted to 28 teachers in post. Statistical analyses of the data confirmed the first as well as the second hypotheses. The researchers offered a range of recommendations, some of which emphasized the use of modern technology that came as a net result of the Web 2.0 revolution in developing the educational process.
\end{abstract}

Index Terms-Ubiquitous learning, u-learning, RSS 2.00, electronic training, applied research, social media.

\section{INTRODUCTION}

Latest interest in the IT and Communications field is that of Ubiquitous Computing [1]. Ubiquitous Learning (u-learning) is rooted in ubiquitous computing technology and enables anyone to learn anything without any time or location constraints. Mobile technology is the perfect platform for anytime, anywhere learning (m-learning), therefore, it fully complements u-learning [2].

"The u-learning community is an interactive social lea/rning model designed in consideration of some factors that mainly influence the learning process of a learner - member of the Internet generation" [3].

Advances in technologies such as context awareness (e.g. sensors), and wireless communication which together make up the base for Ubiquitous computing have gelled together to construct an innovative learning environment [4]. Ubiquitous systems contain functions which monitor, collect and record learning events or a learner's behavior patterns during learning tasks or activities [5].

According to J. S. Sung [6], u-learning is no longer merely a new educational concept or procedure but is, in fact, a

Manuscript received December 4, 2014; revised February 4, 2015.

Mohammad A. Amasha is with the Faculty of Specific Education, Computer Department, Domyat University, Egypt Computer Department, Qassim University Saudi Arabia, Saudi Arabia (e-mail: mw_amasha@yahoo.com).

Salem Alkhalaf is with College of Science and Arts, Computer Department, Qassim University Alrass City, Saudi Arabia (e-mail: s.alkhalaf@qu.edu.sa). system that is deeply integrated with our lives. The transfer of knowledge isn't restricted to the confines of a classroom; it takes place everywhere an individual goes since the transfer of knowledge is primarily dependent upon one's interaction with other people.

According to P. S. Tsai et al. [7], ubiquitous learning has recently become a rather popular form of learning amongst young students and it can be expected to see a lot more of this method of learning in the future. This makes this a key research area for educationalists who need to develop systems in accordance with the changing trends in learning.

It is important to mention that U-learning goes side by side with the rapidly changing technological environment of the world [8]. This form of learning has been making good use of several technological facilities including Smartphones, RFID, mobile IP, sensory technology and several other forms of technology.

The development of social media networking has led to an increased interest amongst researchers to understand and evaluate the important role that social media plays in u-learning. Individuals involved in research in the Computer Supported Cooperative Work (CSCW) mainly study the impacts that social media has on ubiquitous learning and they make their findings public via RSS [9]. owing to the fact that this method allows for information to be continuously altered and brought up to date [10].

According to M. Edward [10], RSS is the most popular internet technology for the promotion and immediate distribution of information that is present online. This method of distributing information has transformed the manner in which the data available online is used. This particularly applies to rapidly changing data [11].

With the help of RSS feed, one can have complete control over the stream of data that is available on the internet whether it is inside or outside the confines of a classroom [12]. Despite the fact that it has been given the title of 'the name game' just like a variety of other XML-based technologies, it can be seen that it has been significantly slow to capture a significant niche online. While it is true that at present a number of websites are making use of RSS in order to distribute their information as it gets updated, the main user base of RSS still consists of individuals who started using it at an early stage [13].

With the help of RSS, mobile technology has been becoming popular as well and is growing significantly. Basically, mobile learning or m-learning involves the use of wireless technology and devices to promote learning without being restricted to one place and while having the liberty to move around [14] Mobile learning has introduced a new method of incorporating learning in our everyday lives [15]. 
It is important to mention the fact that m-learning has several different definitions used in various studies. This primarily suggests that this field of study is not yet fully evolved and that the use of m-learning and the entire concepts itself is still developing. Another important fact that should be mentioned here is that there is a very ambiguous difference between e-learning and m-learning in most studies [9]. The use of this form of learning extends, but is not restricted to, the use of mobile SMS services, online announcements and the use of social media sites such as Facebook by the university for various courses etc [16].

A number of individuals conducting research on u-learning and RSS use the model that has been proposed and tested by Mohd Norazah et al. [17]. The Technology Acceptance Model (TAM) can be effectively used in order to give reasons behind the widespread use of m-learning in which an individual can attain data and information via his or her cellular device. There are several different processes that can lead to a multiple-platform u-learning program to promote the learning of languages with the help of technologies such as interactive television (iTV) and mobile devices [18]. Personalized Knowledge Awareness Map (PERKAM) is a platform that has been introduced by a study by M. Moushir et al. [9] that brings into light a u-learning computing mechanism that assists users as they perform several different tasks. Another study by T. Hall et al. [19] elaborates upon the development of a process that was developed to understand and expand on various techniques of learning that involve direct interaction. This design made use of u-computer technology in order to be able to encourage interaction and interest in learning amongst young individuals in a museum visit.

\section{The PRoBlem IN CONTEXT}

In spite of the fact that a host of teachers have excellent access to the use of modern social media, whether computers, mobile telephones, or any other device connected to the Internet, there is a severe shortage in teachers' skills of using web-based educational applications. By and large, they do not deal with such a technology in an efficient and effective manner.

Accordingly, it is of paramount importance to take into consideration the training of general-education teachers in the use of such types of technologies of the educational applications of the web, putting them in contact with the technology of the next generation, so teachers are able to make use of such technologies in developing their performance, and in the development of e-learning environments. Such efforts aim at ensuring the great access of a large scale of students to e-learning.

The results of the questionnaire addressed to the teachers cast light on a number of problems facing teachers in the process of training. Such problems as a result of a shortage of time as well as teaching and administrative loads drive them away from attending such trainings, and may lead them to seek excuses not to attend the course, or may even attend it in a formal way that does not accrue too much benefit. In spite of the fact that there is the evident satisfaction of knowing that such training is crucially important, and a large section of the budget is assigned to it, making use of such trainings is of little advantage. This was affirmed by the results of the questionnaire. The place, time, and environment of the training proved to be unsuitable.

Development in the field of communication and information technology, the wide spread of electronic knowledge, access to personal digital assistants, and development in the use of mobile telephones have all urged researchers in the field of technology to find apt ways to cope with the developments of the age and to augment the status quo of education in terms of anytime, anywhere access.

The current research attempts to make use of such progress in using the modern technology of podcasting as an instructional model of u-learning. It also makes use of social media networks (Facebook) as a model of social communication in order to solve some of the problems teachers face in training. It attempts to find solutions for the resistant attitudes some teachers have toward training.

The research proposes a training method for teachers. It invests in technological development using the technology of RSS 2.0 as a model of u-learning and mobile instruction. It makes use of social media networks (Facebook) as a model of social communication. This is an attempt to find solutions for problems that teachers face in training. The research assesses also the effect of the proposed program.

\section{PROBLEM OF THE RESEARCH}

From the aforementioned overview, it becomes evident that general-education teachers do not have enough knowledge about the instructional applications of the web. This is the case in spite of the fact that the majority of them already possess modern communication devices, most of which are Internet connected. Most of those teachers are apt to download smart-technology programs. However, they do not know well how to deal with such technologies, which both the teacher and the student can make use of in order to ease communication. This being the case, the current research attempts to answer the following main question:

What is the effect of a proposed training program based on integrating RSS 2.0 technology as a model of u-learning and social media network on developing some skills of the instructional applications of the web?

The research assesses the effect of the program on general-education teachers' performance and attitudes.

Out of such a main question, the following sub-questions were posed:

1) What is the proposed form of a training program based on integration between RSS 2.0 as a model of u-learning and social media networks that is used for developing some skills of using instructional applications of the web by general-education teachers?

2) To what extent is the suggested program using integration between RSS 2.0 as a model of u-learning and social media networks effective in developing the cognitive portion of the skills of instructional applications of the web for general-education teachers?

3) To what extent is the proposed program using integration 
between podcasting and social media networks effective in developing the performance of instructional application skills of the web as for general-education teachers?

To what extent is the proposed training program effective in developing attitudes toward integration between RSS 2.0 as a model of u-learning and social media networks for general-education teachers?

\section{RESEARCH METHOD}

In order to keep up with the nature and objectives of the current research, the researchers depended on the descriptive-analytical method in preparing the theoretical background, the proposed training program, and research tools. Moreover, the research utilized the experimental method in order to assess the effectiveness of the proposed program.

\section{A. Research Variables}

The current research manipulated the effect of an experimental variable on three dependent ones.

\section{B. Experimental Variable}

This training program was proposed in order to develop the skills of instructional applications of the web. It is based on integration between RSS 2.0 as a model of u-learning and social media networks (Facebook).

\section{Independent Variables}

1) Achievement in the cognitive portion of some skills of the instructional applications of the web.

2) Development of the applicative portion of some skills of the instructional applications of the web.

3) Development in attitudes toward using RSS 2.0 as a technological model of u-learning.

\section{Composition of the Study Sample}

The population of the current study was composed entirely of general-education teachers (primary-intermediate-secondary). The sample participants were chosen specially from Rass Educational Directorate, Qassim Province, K.S.A. The sample amounted to 28 teachers. Prerequisites for conducting the research were already available for the sample participants. Researchers selected the sample participants in coordination with the administration of training and educational supervision as follows:

1) Teachers' awareness of skills of using the computer as a prerequisite.

2) Teachers' commitment to attending training courses held by the directorate.

The researchers used a one-group experimental design. Tests were administered before and after administering the program. Differences were assessed according to the performance of the group both before and after experimentation.

\section{E. Designing the Experimental Material}

- The preliminary lecture was recorded in order to brief the sample participants concerning the objectives of the training program, its relative significance, and its executive procedures. Moreover, methods of assessment were made clear.

- A Facebook page was created in order to communicate with the trainees. The page was connected to RSS 2.0 so that lectures were transmitted as soon as they were uploaded via iTunes using a mobile smart phone (iPhone-android). In addition, the settings for the trainees' Facebook pages were manipulated on their PCs, following these procedures:

- The application RSS was added to the researchers private account on Facebook, http://www.facebook.com/?ref=home, as follows:

A link for extracts, RSS Feed to the Fan Page wall, was added to each trainee's Facebook page.

A group of trainees was created (Group RSS 2.0). Trainees were added after sending each of them an invitation at this link:

http://www.facebook.com/home.php?sk=group_2170994549 74432 \&ap $=$

A link for extracts, RSS Feed, was added to the page of the group, and it was linked to the trainees' Facebook Fan Page wall.

\section{RESULTS OF THE RESEARCH AND INTERPRETATIONS}

In order to answer the first research question - "What is the proposed form of a training program based on integration between RSS 2.0 as a model of u-learning and social media networks that are used for developing some skills of using instructional applications of the web by general-education teachers?"- the proposed training program was designed aiming at developing some skills of using instructional applications of the web via using media-transmission technology, RSS 2.0 as well as social media networks (Facebook). This was explained in the section previously cited regarding research procedures.

In order to answer the second question-"To what extent is the suggested program using integration between RSS 2.0 as a model of u-learning and social media networks effective in developing the cognitive portion of the skills of instructional applications of the web for general-education teachers?"- the first hypothesis was tested. The hypothesis goes as follows:

"There are statistically significant differences at the 0.05 level between the mean scores of general-education teachers in the pre and post administrations of the achievement test in achievement of the cognitive portion of the skills of the instructional applications of the web using integration between RSS 2.0 as a model of u-learning and social media networks in favor of the post."

A t-test was used in order to test this hypothesis using SPSS. Table I illustrates the results of the t-test for the significance of differences between mean scores of the general-education teachers in the pre and post administrations of the achievement test concerning the cognitive portion of the skills of the instructional applications of the web using integration between RSS 2.0 as a model of u-learning and social media networks (Facebook).

As is shown in the table, there are statistically significant 
differences at 0.05 between the mean scores of the general-education teachers $(27, N=28)=17.36 p=.05$ in the pre and post administrations of the test of the cognitive portion of skills of using instructional applications of the web in favor of the post administration. Henceforth, the first hypothesis was accepted. This indicates that the independent variable of the research-that is, the training program-proved to be effective in developing the aforementioned skills.

TABLE I: RESUlTS OF A T-TEST FOR THE SIGNIFICANCE OF DIFFERENCES IN MEAN SCORES OF GENERAL-EdUCATION TEACHERS IN THE PRE AND POST ADMINISTRATIONS OF THE TEST OF ACHIEVEMENT IN THE COGNITIVE PORTION OF SKILLS OF INSTRUCTIONAL APPLICATIONS OF THE WEB

\begin{tabular}{lccccc}
\hline \hline Test & $M$ & $S D$ & $d f$ & $t$-test & Sig. \\
& & & & & \\
\hline Pre & 13.68 & 3.14 & 27 & 17.36 & 0.000 \\
& & & & & \\
Post & 27.86 & 2.07 & & & \\
\hline \hline
\end{tabular}

$* P<.05 .{ }^{* * P<.01}$

In order to determine the applicative significance of the independent variable (the suggested training program) upon the dependent variable (achievement of the cognitive portion of the skills), an eta squared was calculated. This expresses the relative effect of the first variable on the second one. The effect is relatively small if it amounts to 0.01 , medium if it amounts to 0.06 , and great if it amounts to 0.14 . Table II shows the results of the eta squared.

TABLE II: MAgnitude EFFECT OF THE IndEPENDENT VARIABLE (THE Proposed Training Program) ON DEveloping the DePendent VARIABLE (ACHIEVEMENT OF THE COGNITIVE PORTION OF SKILLS OF USING INSTRUCTIONAL APPLICATIONS OF THE WEB) USING THE ETA SQUARED

\begin{tabular}{ccc}
\hline \hline$d f$ & $t$-value & $\eta^{2}$ \\
& & \\
\hline 27 & 17.36 & 0.92 \\
\hline
\end{tabular}

It is evident from Table II that the eta squared value is $0.92>0.14$. This means that the magnitude effect (the proposed training program) was effective in developing some skills of the general-education teachers in using instructional applications of the web. The effect was quite significant. It indicates the effectiveness of the program in developing the achievement of those teachers using integration between technologies of RSS 2.0 as a model of u-learning and social media networks (Facebook).

This result is in line with the results reached by Alpay and Gulati (2010), which illustrated that the use of RSS 2.0 as a model of u-learning in broadcasting lectures and lessons proved the effectiveness of the proposed model broadcast via RSS 2.0.

In order to answer the third question-"To what extent is the proposed program using integration between podcasting and social media networks effective in developing the performance of the instructional-application skills of the web by general-education teachers?"- the second hypothesis of the study was tested. It states, "There are statistically significant differences at the 0.05 levels between the mean scores of general-education teachers in the pre and post administrations of the evaluation checklist of the applicative portion of some skills of using the web using integration between u-learning and social media networks in favor of the post."

In order to test such a hypothesis, a t-test was used. Table (3) illustrates the results of the t-test for significant differences between the mean scores of general-education teachers in the pre and post administrations of the checklist evaluating applicative aspects of some skills of using instructional applications of the web using integration between RSS 2.0 as a model of u-learning and social media networks (Facebook).

TABLE III: REsults OF THE T-TeST FOR THE SignificANCE OF DiFFERENCES BETWEEN THE MEAN SCORES OF GENERAL-EDUCATION Teachers in the Pre and Post Administrations of THE Checklist of APPLICATIVE ASPECTS OF SOME SKILls OF INSTRUCTIONAL APPLICATIONS OF THE WEB

\begin{tabular}{cccccc}
\hline \hline Test & $M$ & $S D$ & $d f$ & t-test & Sig. \\
\hline Pre & 57.89 & 9.36 & 27 & 36.815 & 0.000 \\
Post & 117.71 & 9.09 & & & \\
\end{tabular}

$* P<.05 . * * p<.01$.

The results in Table III indicate that there are statistically significant differences at $<=0.05$ between the mean scores of general-education teachers $(27, N=28)=36.815, p=.05$ in the pre and post administrations of the checklist of the applicative side of some skills of using the instructional applications of the web in favor of the post. Henceforth, the second hypothesis was accepted. This indicates that the independent variable, the proposed program, was effective in developing the applicative side of some skills of using the instructional applications of the web.

In order to determine the applicative significance of the independent variable (the proposed training program) on the dependent variable (achievement in the cognitive side), an eta squared was calculated. This determines the magnitude effect of the first variable on the second. Table IV shows the eta squared value.

TABLE IV: MAgnitude EFFECT OF THE InDEPENDENT VARIABLE (THE Training Program) ON DEVEloping the DePendent Variable (APPlicative SidE OF SOME Skills OF Using THE INSTRUCTIONAL APPLICATIONS OF THE WEB AS TESTED BY AN ETA SQUARED)

\begin{tabular}{ccc}
\hline \hline$d f$ & $t$-Value & $\eta^{2}$ \\
& & \\
\hline 27 & 36.815 & 0.98 \\
& & \\
\hline \hline
\end{tabular}

It is evident from Table IV that the eta squared is $0.98>$ 0.14 . This proves the magnitude effect of the training program on developing the applicative aspects of some skills of using instructional applications of the web by general-education teachers using integration between RSS 2.0 technology as a model of u-learning and social media networks (Facebook).

Referring to the results of the second and third questions of the current research, the proposed program proved to be effective in developing the cognitive and applicative aspects of some skills of using instructional applications of the web using integration between RSS 2.0 technology as a model of u-instruction, social media networks, and using Facebook as a model for general-education teachers, the sample of the study.

Therefore, it can be said that the program proved to be effective in rendering its purposes. 
The results can be attributed the following:

The inherent nature of the research as well as the proposed method of training; that is, using the technology of RSS 2.0 as a medium for broadcasting serials of the proposed program and getting in contact with trainees via the Facebook page that was created for that purpose. The issue of the training itself is a modern innovation of modern technology within the province of electronic learning. This gave the trainees a momentum to master the specified skills. Moreover, they exerted efforts in order to deal with the method used in broadcasting the sessions of the program.

- The method used in training enabled the trainees at anytime anywhere to get access to listen to the lectures using mobile telephones and tablets. The trainees reacted to this with much enthusiasm.

- The content of the training program made it feasible for the trainees to put what they have learned into practice while teaching their students. This was quite evident from the sample whose members asked to get access to the broadcasting method used in the current research in order to use it while communicating with their students.

- Conducting the experiment via a Facebook page at a time that suits the trainees enabled the trainees to learn and use the skills quite easily.

- The variety in methods and styles of training broadcast through instructional presentations, sound files, conversations, and oral and written dialogues among trainees provided a variety of experiences for the teachers. To answer the fourth question-"To what extent is the proposed training program effective in developing attitudes toward integration between RSS 2.0 as a model of u-learning and social media networks by general-education teachers?"- the third hypothesis of the research was tested. The hypothesis is as follows:

"There are statistically significant differences at the 0.05 level between the mean scores of general-education teachers in the pre and post administrations of the attitude scale as per the use of integration between RSS 2.0 as a model of u-learning and social media networks in studying the suggested program in favor of the post."

A t-test was used to verify the hypothesis. Table V illustrates the results of the t-test concerning the significance of differences between the mean scores of general-education teachers in both the pre and post administrations of the attitude scale concerning the use of integration between RSS 2.0 technology as a model of u-learning and social media networks (Facebook) in studying the proposed program.

TABLE V: RESULTS OF THE T-TEST FOR THE SIGNIFICANCE OF DIFFERENCES BETWEEN THE MEAN SCORES OF GENERAL-EDUCATION TEACHERS IN THE PRe AND Post Administrations of the ATtitude SCALE ConCERning THE USE OF RSS 2.0 AS A MOdel OF U-LeARning AND Social Media NETWORKS

\begin{tabular}{lccccc}
\hline \hline Test & $M$ & $S D$ & $d f$ & $t$-test & Sig. \\
\hline Pre & 59.25 & 10.341 & 27 & 36.592 & 0.000 \\
Post & 144 & 6.383 & & & \\
& & & & & \\
\hline \hline$<.05 . * * P<.01$. & & &
\end{tabular}

The results in Table $\mathrm{V}$ indicate that there are statistically significant differences at $<=0.05$ between the mean scores of the general-education teachers' scores $(27, N=28)=36.592$, $p=.05$ in the pre and post administrations of the attitude scale by the use of RSS 2.0 as a model of u-learning and social media networks in favor of the post administration. Therefore, the last hypothesis was confirmed. This illustrates that the independent variable, the suggested program, was effective in developing attitudes toward using RSS 2.0 as a model of u-learning and social media networks while studying the suggested program.

In order to specify the applicative significance of the independent variable, the suggested training program, as regards the dependent one, cognition, an eta squared was calculated. This illustrates the magnitude effect of the first variable on the second. Table VI illustrates the results of the eta squared.

TABLE VI: MAGNitude EFFECT OF THE INDEPENDENT VARIABLE (THE Suggested Training Program) on Developing the DePendent VARIABLE (ATTITUDES TOWARD USING RSS 2.0 AS A MODEL OF USING U-Learning AND Social MEdia Networks) as TeSted by AN ETA SQUARED

\begin{tabular}{ccc}
\hline \hline $\mathrm{df}$ & $t$-value & $\eta 2$ \\
\hline 27 & 36.592 & 0.98 \\
\hline \hline
\end{tabular}

It is quite evident from Table VI that the eta squared value is $0.98<0.14$. This signifies the magnitude effect of the suggested program on developing the applicative aspects of some skills of using instructional applications of the web by general-education teachers. The effect is very significant. It indicates the effectiveness of the program in developing the attitudes of general-education teachers toward using RSS 2.0 as a model of u-learning and social media networks while studying the training program.

Improvements in the students' attitudes toward integration between RSS 2.0 as a model of u-learning and social media networks while studying the suggested program may be attributed to a number of factors, among which are the following:

- Using RSS 2.0 as a model of u-learning and the integration therein with the use of Facebook while studying the program created an apt electronic environment, which was new for the teachers. This gave them momentum for their curiosity to find out about modern technology.

- Training teachers in some practical applications of the web caused them to feel quite deeply that making use of such applications was very important. The teachers' fear was eliminated while dealing with different applications of the web as well as those of instructional technology.

- RSS 2.0 used in the current research delivers the instructional content directly to the PC or mobile phone. It can transmit such a content directly to the Facebook page as soon as the link is downloaded. This method developed the teachers' positive attitudes toward the method employed. It enabled them to learn quite freely. They did not have to attend regular training sessions, for which they may not have had enough time. Variety in the learning resources used aided the trainees to have positive attitudes toward the method employed in the current research.

\section{RESEARCH RECOMMENDATIONS AND SUGGESTIONS}

Referring back to the aforementioned results of the present 
research intended to measure the effectiveness of the suggested training program in developing some uses of the practical applications of the web using integration between RSS 2.0 as a model of u-learning and social media networks by general-education teachers, the researchers recommend the following:

1) Using the suggested training program not only for general-education teachers, but also for training student-teachers in various educational stages. The program can be listed among teacher-preparation programs in faculties of education.

2) Using the suggested training method used in the research, i.e., integration between RSS 2.0 as a model of u-learning and social media networks in order to develop electronic-learning programs in coordination with a learning management system (LMS).

3) Developing teacher-training programs in accordance with variables of the modern age, such as dealing with social networks via the internet, electronic symposia, direct conversation, emails, educational blogs, etc.

4) Making use of and developing distant-training programs in accordance with the teachers' conditions while taking into consideration their commitments. Teachers should be given more freedom in their training. Moreover, they should be encouraged to join such training programs.

5) Engaging teachers in continuous applications of the web and making good use of its advantages in order to strengthen communication between the teacher and his or her students. Uses can extend to include teaching presentations, electronic-test design, and jotting lessons down.

6) Making good use of social media networks in order to develop teachers' performance and communication with students.

7) Conducting a total revision of teacher-training programs in faculties of education in order to keep up with advances in modern technology.

Setting a certain mission as well as clear objectives for teacher training in accordance with the requirements of the modern age. This should be done in the light of the nature of the society. The absence of such a clear vision is highly undesirable during this stage of establishing the history of our country.

\section{REFERENCES}

[1] S. Yahya, E. A. Ahmad, and K. A. Jalil, "The definition and characteristics of ubiquitous learning: A discussion," International Journal of Education and Development Using Information and Communication Technology, vol. 6. issue 1, pp. 117-127, 2010.

[2] M. Shanmugapriya and A. Tamilarasi, "Designing an m-learning application for a ubiquitous learning environment in the android based mobile devices using web services," Indian Journal of Computer Science and Engineering (IJCSE), vol. 2, no. 1, pp. 22-30, 2012.

[3] T.-S. Kim, "Towards the design of an interactive u-learning system," Journal of Security Engineering, vol. 9, no. 2, pp. 190-198, 2012.

[4] G. J. Hwang, H. C. Chu, Y. S. Lin, and C. C. Tsai, "A knowledge acquisition approach to developing mind tools for organizing and sharing differentiating knowledge in a ubiquitous learning environment," Computers \& Education, vol. 57, pp. 1368-1377, 2011.

[5] W. Ting-Ting et al., "A systematic approach for learner group composition utilizing u-learning portfolio," Educational Technology \& Society, 2012

[6] J.-S. Sung, "U-learning model design based on ubiquitous environment," International Journal of Advanced Science and Technology, vol. 13, 2009.

[7] P.-S. Tsai et al., "Developing a survey for assessing preferences in constructivist context-aware ubiquitous learning environments," Journal of Computer Assisted Learning, pp. 250-264, June 2012.

[8] D. Caytiles et al., "Design of an effective WSN-based interactive u-learning model," International Journal of Distributed Sensor Networks, p. 12, 2012.

[9] M. Moushir et al., "Social knowledge awareness map for computer supported ubiquitous learning environment," vol. 13, no. 4, pp. $1436-4522,2010$

[10] M. C. Edward and L. M. Heather, "Integrating RSS feeds of new books into the campus course management system," Computers in Libraries, vol. 26, no. 9, 2007.

[11] J. W. L. Mark, M. Charlynn, and N. Leon, "RSS and content syndication in higher education: Subscribing to a new model of teaching and learning," Educational Media International, vol. 45, no. 4, pp. 311-322, 2008.

[12] R. Will, "Merrily down the Stream: RSS makes it easy to gather information," School Library Journal, vol. 52, no. 7, p. 40, 2007.

[13] J. G. Ronald et al., "Syndicated RSS feeds for course information distribution," Journal of Information Technology Education, pp. 163-183, 2008.

[14] P. Yeonjeong, "A pedagogical framework for mobile learning: Categorizing educational applications of mobile technologies into Four types," International Review of Research in Open and Distance Learning, vol. 12, no. 2, pp. 78-102, 2011.

[15] T.-Y. Liu, "A context-aware ubiquitous learning environment for language listening," Journal of Computer Assisted Learning, vol. 25 no. 6, pp. 515-527, 2009.

[16] V. Benson and S. Morgan, "Student experience and ubiquitous learning in higher education: Impact of wireless and cloud applications," Creative Education, vol. 4, no. 8A, pp. 1-5, 2013.

[17] S. N. Mohd, "Users' behavior towards ubiquitous m-learning," Turkish Online Journal of Distance Education, vol. 12, no. 3, pp. 1302-6488, 2011.

[18] F. Sanaz et al., "Development of a cross-platform ubiquitous language learning service via mobile phone and interactive television," Journal of Computer Assisted Learning, vol. 23, no. 4, pp. 312-325, 2007.

[19] T. Hall and L. Bannon, "Designing ubiquitous computing to enhance children's learning in museums," Journal of Computer Assisted Learning, vol. 22, no. 4, pp. 231-243, 2006.

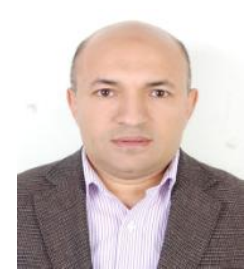

Mohamed Amasha was born in Egypt, Domyat in 1970. He is an associate professor in the application of computer in education, Domyat University Egypt, Qassim University Saudi Arabia 2012.

$\mathrm{He}$ works as a lecturer and an associate professor in Qassim University. He has published in A.U.C in Egypt, IJACSA, IJORCS.

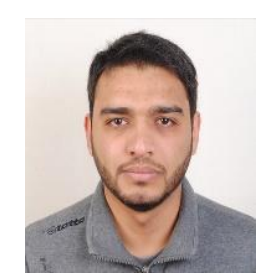

Salem Alkhalaf was born in Alrass city, Kingdom of Saudi Arabia. He is an assistant professor in Computer Department, College of Science and Arts in Al-Rass, Qassim University. $\mathrm{He}$ graduated with the bachelor of education degree in computer since from the Department of Computer, Teachers College (Riyadh) in 2003. Also he graduated with honors degree. And he graduated the master of ICT from Griffith University (Brisbane, Australia) in 2008. He graduated with the $\mathrm{PhD}$ in ICT from Griffith University (Gold Coast, Australia). Finally, he is interested in developing e-learning environments for universities especially in KSA . 